\title{
Analysis of reasons for discarding of blood and blood products in a tertiary care hospital
}

\author{
Mourouguessine V. ${ }^{1 *}$, Balla R. ${ }^{2}$, Anandabaskar N. ${ }^{3}$ \\ DOI: https://doi.org/10.17511/jopm.2019.i08.02 \\ 1* Vimal Mourouguessine, Associate Professor, Department of Pathology, Sri Manakula Vinayagar Medical College and Hospital, Puducherry, \\ India. \\ 2 Rakesh Balla, Undergraduate Student, Department of Pathology, Sri Manakula Vinayagar Medical College and Hospital, Puducherry, India. \\ 3 Nishanthi Anandabaskar, Assistant Professor, Department of Pharmacology, Sri Manakula Vinayagar Medical College and Hospital, \\ Puducherry, India.
}

Introduction: A quality management system should be followed at all stages of collection, processing, storing and issuing of blood products. Hence it is vital to know the discarding of blood products at the blood banks to improve the transfusion services and for effective management of the blood products. Aim: To find the various reasons for discarding of blood products and to explore the strategies to minimize its wastage in the blood bank of a tertiary care hospital. Materials and methods: Data was collected from the master blood donor register, whole blood and components record and discarding register for a period of three years. The information on total blood products prepared, total number of products discarded and the reason for discarding was retrieved from these records. Results: In the study period, expiry was the main reason for discarding of whole blood and platelets. Packed cells were discarded due to expiry, Transfusion transmissible infections and damaged bag. Damaging due to the handling was the common reason for discarding of FFPs and none of the Cryoprecipitate was discarded. Hepatitis B infection was the most common cause of Transfusion transmissible infection followed by Syphilis in the present study. Conclusion: Meticulous screening of donors prior to blood donation, sensitizing the clinicians on rational use of blood products, training of blood bank personnel and practicing standard transfusion protocols will minimize the discard rate of blood and blood products in the blood banks.

Keywords: Quality management system,Discarding of blood products, Transfusion transmissible infections, Rational use of blood products, Standard transfusion protocols

Corresponding Author

Vimal Mourouguessine, Associate Professor, Department of Pathology, Sri Manakula Vinayagar Medical College and Hospital, Puducherry, India. Email: drvimalm@gmail.com

\section{How to Cite this Article}

Mourouguessine V, Balla R, Anandabaskar N. Analysis of reasons for discarding of blood and blood products in a tertiary care hospital. Trop J Pathol Microbiol. 2019;5(8):517-522.

Available From

https://pathology.medresearch.in/index.php/jopm/ar ticle/view/298

\section{To Browse}

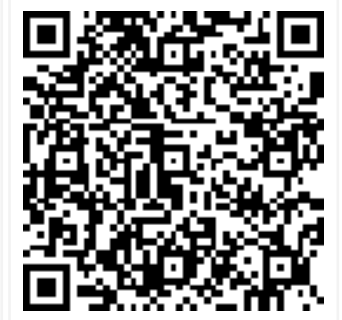

Manuscript Received 2019-07-14

Conflict of Interest No
Review Round 1 2019-07-24

Funding $\mathrm{Nil}$

Review Round 2
2019-07-30
$\begin{gathered}\text { Ethical Approval } \\ \text { Yes }\end{gathered}$

Review Round 2 Yes
Review Round 3

Plagiarism X-checker $9 \%$
Accepted 2019-08-05

Note

(c) 2019 by Vimal Mourouguessine, Rakesh Balla, Nishanthi Anandabaskar and Published by Siddharth Health Research and Social Welfare Society. This is an Open Access article licensed under a Creative Commons Attribution 4.0 International License https://creativecommons.org/licenses/by/4.0/ unported [CC BY 4.0]. 


\section{Introduction}

Transfusion services are aimed to provide blood and blood products as per the patient's requirements ensuring the safety of the issued products. The increase in modern surgical procedures and advancement in technologies have increased the need for the blood transfusion multifold. There is always an unmet demand for blood products, effective transfusion services should be aimed at improving the resources for collection of blood and blood products or efficiently utilizing the existing blood products [1].

Hence a quality management system should be followed at all stages of collection, processing, storing and issuing of blood products. Hence it is vital to know the discarding of blood products at the blood banks to improve the transfusion services and also to effective management of the blood products. By analyzing the reasons for discarding, strategies can be followed to minimize the discarding rate to save time, human and financial resources [2]. Thus this study was aimed to find out the various reasons for discarding of blood products and to explore the strategies to minimize its wastage in the blood bank of a tertiary care hospital.

\section{Materials and Methods}

Setting, duration and type of study: This was a retrospective cross sectional study carried out in the
Blood bank of atertiary care hospital for a period of three years from January 2015 to December 2017.

Data collection: Data was collected from the master blood donor register, whole blood record, blood components record and blood products discarding register of the Blood bank.

The information on total blood products prepared, total number of products discarded and the reason for discarding was retrieved from these records.

Data analysis: Data was collected in a structured data collection form, entered in an excel spreadsheet and data were analyzed by calculating the frequency and percentage of the variables.

\section{Ethical consideration and permission:} Permission was obtained from the Institutional ethics committee before the commencement of the study and all the ethical principles were adhered throughout the study.

\section{Results}

A total of 4403 blood products were collected in the year 2015, out of which 1011 were discarded, with nearly $56.3 \%$ of platelets were discarded, followed by $20.3 \%$ of whole blood. In 2016, out of 4924 blood products prepared, 906 were discarded which included $43 \%$ of platelets and $12 \%$ of FFP. Out of 7928 blood products collected on 2017, 1173 units were discarded out of which $31.4 \%$ were platelets, followed by $22.4 \%$ of whole blood.

Table-1: Discardance rate of the blood and blood products during the study period.

\begin{tabular}{|c|c|c|c|c|c|c|c|}
\hline \multirow[t]{2}{*}{ Year } & \multirow[t]{2}{*}{ Collection and discarding } & \multirow[t]{2}{*}{ Whole blood N/\% } & \multicolumn{4}{|c|}{ Components } & \multirow[t]{2}{*}{ Total N } \\
\hline & & & Packed cells N/\% & Platelets N/\% & FFP N/\% & Cryo $\mathrm{N}$ & \\
\hline \multirow[t]{3}{*}{2015} & Collected & 758 & 1215 & 1215 & 1215 & 0 & 4403 \\
\hline & Discarded & 154 & 74 & 685 & 98 & 0 & 1011 \\
\hline & Discardancerate & $20.31 \%$ & $6.09 \%$ & $56.37 \%$ & $8.06 \%$ & 0 & \\
\hline \multirow[t]{3}{*}{2016} & Collected & 898 & 1342 & 1342 & 1342 & 0 & 4924 \\
\hline & Discarded & 76 & 85 & 578 & 167 & 0 & 906 \\
\hline & Discardancerate & $8.46 \%$ & $6.33 \%$ & $43.07 \%$ & $12.44 \%$ & 0 & \\
\hline \multirow[t]{3}{*}{2017} & Collected & 716 & 2404 & 2404 & 2404 & 0 & 7928 \\
\hline & Discarded & 161 & 76 & 756 & 180 & 0 & 1173 \\
\hline & Discardancerate & $22.48 \%$ & $3.16 \%$ & $31.44 \%$ & $7.48 \%$ & 0 & \\
\hline
\end{tabular}

Table-2: Reasons for discarding blood and blood products during the study period

\begin{tabular}{|c|l|l|l|l|l|l|}
\hline \multirow{2}{*}{ Year } & \multicolumn{2}{|c|}{ Blood product } & \multicolumn{5}{c|}{ Total } \\
\cline { 3 - 8 } & & Expiry N/\% & TII N/\% & Damaged N/\% & Clerical error N/\% \\
\hline \multirow{3}{*}{2015} & WB & $130(84.4 \%)$ & $24(15.6 \%)$ & 0 & 0 & 154 \\
\cline { 2 - 8 } & PC & $43(58.1 \%)$ & $30(40.5 \%)$ & $1(1.35 \%)$ & 0 & 74 \\
\cline { 2 - 8 } & PLT & $647(94.4 \%)$ & $34(4.9 \%)$ & $4(0.5 \%)$ & 0 & 685 \\
\cline { 2 - 8 } & FFP & 0 & $34(34.6 \%)$ & $63(64.2 \%)$ & $1(1.02 \%)$ & 98 \\
\hline
\end{tabular}




\begin{tabular}{|l|l|l|l|l|l|l|}
\hline & CRYO & 0 & 0 & 0 & 0 & 0 \\
\hline \multirow{5}{*}{2016} & WB & $58(76.3 \%)$ & $18(23.6 \%)$ & 0 & 0 & 76 \\
\cline { 2 - 7 } & PC & $23(27.1 \%)$ & $1(1.17 \%)$ & $61(71.7 \%)$ & 0 & 85 \\
\cline { 2 - 7 } & PLT & $518(89.6 \%)$ & $20(3.46 \%)$ & $40(6.9 \%)$ & 0 & 578 \\
\cline { 2 - 7 } & FFP & $4(2.39 \%)$ & $15(8.9 \%)$ & $148(88.6 \%)$ & 0 & 167 \\
\cline { 2 - 7 } & CRYO & 0 & 0 & 0 & 0 & 0 \\
\hline \multirow{5}{*}{2017} & WB & $109(67.7 \%)$ & $1(0.62)$ & $51(31.6 \%)$ & 0 & 161 \\
\cline { 2 - 7 } & PC & $22(28.9 \%)$ & $54(71.1 \%)$ & 0 & 0 & 76 \\
\cline { 2 - 7 } & PLT & $688(91 \%)$ & $40(5.29 \%)$ & $28(3.7 \%)$ & 0 & 756 \\
\cline { 2 - 7 } & FFP & $17(9.4 \%)$ & $15(8.3 \%)$ & $148(82.2 \%)$ & 0 & 180 \\
\cline { 2 - 7 } & CRYO & 0 & 0 & $544(17.6)$ & $1(0.03)$ & 3090 \\
\hline
\end{tabular}

Table-3: Reasons for discarding blood and blood products due to Transfusion Transmissible Infections during the study period.

\begin{tabular}{|l|l|l|l|l|l|l|}
\hline \multirow{2}{*}{ Year } & \multicolumn{5}{|c|}{ Transfusion transmissible Infections } & \multirow{2}{*}{ Total N } \\
\cline { 2 - 7 } & HIV N/\% & HBSAg N/\% & HCV N/\% & VDRL N/\% & Malaria N/\% & \\
\hline 2015 & $4(3.3 \%)$ & $94(77.6 \%)$ & $3(2.5 \%)$ & $18(14.9 \%)$ & $3(2.5 \%)$ & 122 \\
\hline 2016 & 0 & $33(61.1 \%)$ & $2(3.7 \%)$ & $19(35.1 \%)$ & 0 & 54 \\
\hline 2017 & 0 & $90(81.8 \%)$ & 0 & $20(17.8 \%)$ & 0 & 110 \\
\hline Total & 4 & 212 & 4 & 51 & 3 & 286 \\
\hline
\end{tabular}

Table-4: Comparison of reasons for discarding blood and blood products in present study withvarious published studies

\begin{tabular}{|c|c|c|c|c|c|c|c|c|}
\hline Study & Study duration & Collected units $\mathrm{N}$ & Discarded units $\mathrm{N}$ & TTI & Expired N\% & Less quantity $\mathrm{N} \%$ & Leakage $\mathrm{N} \%$ & Others N\% \\
\hline Kanani et al[3] & 3 years & 66,255 & 4604 & $520(11.3)$ & $1997(43.4)$ & $1169(25.4)$ & $631(13.7)$ & $163(3.5)$ \\
\hline Kora et al[4] & 2 years & 6129 & 263 & $220(83.6)$ & $38(14.4)$ & $5(2.0)$ & - & - \\
\hline Kumar et al[5] & 19 months & 10,582 & 888 & $300(33.8)$ & $513(57.8)$ & $18(2.0)$ & $27(3.0)$ & $20(3.4)$ \\
\hline Morish et al[6] & 1 year & 390,634 & 8968 & - & - & 353 (3.9) & 2306 (25.7) & $6309(70.4)$ \\
\hline Patil et al[7] & 30 months & 14,026 & 2888 & $953(33.0)$ & $1531(53.0)$ & $48(1.7)$ & $97(3.4)$ & $186(6.4)$ \\
\hline Suresh et al[8] & 18 months & 24,847 & 1747 & 663 (37.9) & $131(7.5)$ & $536(30.7)$ & $28(1.6)$ & $78(4.5)$ \\
\hline Thakare et al[9] & 3 years & 24,547 & 879 & $604(68.86)$ & $275(31.3)$ & - & - & - \\
\hline Present study & 3 years & 17255 & 3090 & $286(9.3)$ & $2259(75.3)$ & - & $544(17.6)$ & $1(.03)$ \\
\hline
\end{tabular}

In the study period, expiry was the main reason for discarding of whole blood and platelets, followed by transfusion transmissible infections and damaged blood bags. But the reasons for discarding packed cells varied during the study period. In 2015, expiry $(58.1 \%)$, followed by transfusion transmissible infections (40.5\%) was the common reason, in 2016 damaged bags $(71.7 \%)$ followed by expiry $(27.1 \%)$ was the common reason and in 2017, transfusion transmissible infections (71.1\%) followed by expiry $(28.9 \%)$ was the common reason. In all the three years, damaging due to the handling was the common reason for discarding of FFPs and none of the Cryoprecipitate was discarded. In all the three years of the study period, Hepatitis B infection was the most common cause of transfusion transmissible infection followed by syphilis in the present study.

\section{Discussion}

Advanced medical sciences and emerging newer modalities of treatment have increased the demand for blood and blood products. Hence, blood banks should adopt strategies for the effective processing, management of the transfusion services. The prior goal of effective transfusion services includes minimizing the unnecessary wastage of blood and blood products. The average discard rate of blood and blood components in the present study was $17.9 \%$ which was quite comparable with the previously conducted studies [3-9]. Table 4 signified the comparison of reasons for discarding of blood and blood products in the present study with similar other studies. The major reason for the higher discardance rate in the present study was because of shorter expiry date of platelets. 
The discardance rate of whole blood in the present study was $17 \%$. The most common cause of discardance of whole blood was due to expiry and the other causes include transfusion transmissible infections and damaged blood bags due to leakage of blood, clotted/ hemolysed blood. Patil et al [2] suggested that the main reason for less quantity of the blood was due to the complications of phlebotomy procedure such as adverse donor reaction including uneasiness, fainting attacks, vomiting, and hematoma formation and collapse of vein.

These can be minimized by selection of healthy donors and adequate motivation and support of donors by the blood bank personnel. The instruments in the blood bank should be periodically calibrated to measure the volume of blood in the bag accurately. As component therapy is being encouraged in most blood banks, whole blood was made only on demand for exchange transfusion, microvascular surgeries and cardiothoracic surgeries. If the whole blood was not utilized by the demanding unit, there was a high chance of discarding [10].

The discardance rate of packed cells in the present study was $5.2 \%$. One of the primary reasons for discarding packed cells was the damaged or suboptimal volume which were aliquots issued to the pediatric patients. This issue can be minimized by maintaining proper stock inventory and preparing of aliquots only as per demand with strict aseptic precautions.

The discardance rate of platelets in the present study was $43.6 \%$. The most common cause of discordance of platelet units was because of expiry. This was due to the shorter shelf life of platelets. Hence it is suggested that platelets should be prepared only on demand and aphaeresis will also solve this issue to certain extent.

The discardance rate of FFP in the present study was $9.3 \%$. The common causes of discarding of FFP were due to leakage of the bag, ordered in excess number and non utilization after the issue, contamination with RBCs and lipemic plasma. Keeping the FFP bags in polystyrene protective containers can minimize the wastage of FFP during handling and transportation [11].

The integrity of the blood bags is also an essential factor and due precautions must be taken to prevent leakages [12].
Lipaemic blood products can be prevented by creating donor awareness and meticulous screening before blood collection from donors and insisting to avoid a fatty meal prior to donation.Adequate training of blood bank personnel will minimize the wastage due to suboptimal volume and RBC contamination. Maintaining a voluntary blood donor registry, conduction of blood donation camps during times of appropriate need can be done at the collection phase itself. An active coordination between camp organizers and blood bank personnel during the needs of blood products can help in effective planning and obtaining the blood to the blood bank which can minimize the wastage. Sharing the stock data between the blood banks can help in sharing of the blood products between the donor and recipient blood banks and can minimize the wastage and also improve the effective utilization.

A good communication between the clinician and blood bank personnels will be an effective solution to avoid wastage due to non utilization of blood products after the requisition was made. Meticulous screening with a detailed history taking during the selection of donors for blood donation [13]. This will eliminate the discarding of blood products due to transfusion transmissible infections at the donor screening desk itself. Rapid screening of blood samples for transfusion transmissible infections before phlebotomy can prevent donor blood wastage.

Ideally every blood bank should aim at zero percentage wastage.The storage period of blood products vary as whole blood can be stored for 35 days and packed red cells with Saline Adenine Glucose Mannitol (SAGM) preservative can be stored for 42 days whereas FFP can be stored for a maximum of one year at $-30^{\circ} \mathrm{C}$. Blood products which are nearing expiry can be sorted out during daily stock taking and they can be arranged in front shelves of Blood Bank Refrigerators and platelet agitators.

All Blood banks should follow a FIFO (First in First out) policy which can minimize the discardance rate due to expiry of the products [14]. Following a Type and screen protocol at blood camps which includes screening of other antigens like Bombay, Parabombay, MNS, Kell, Lewis, Duffy and autoantibodiescan decrease the wastage due to expiry as the demand for these blood products is very less. 
The rate of discarding blood products is a quality indicator recommended by National Accreditation Board for hospitals and Health care providers (NABH) [10]. Every institution should have a well functioning Transfusion committee constituted by the Blood bank medical officer, transfusion specialist, Head of departments of pathology and other clinical heads and the Medical superintendent which should frame policies for rational use of blood and blood products which can minimize the discardance rate. Sensitizing the clinicians about the rational use of blood and blood products, their indication and insisting them to return the unused blood products within 15 to 30 minutes to the blood bank after issue with due care taken to maintain the cold chain and sterility.Practicing standard transfusion protocols made by proper policy making and its strict implementation will minimize the discard rate of blood and blood products in the blood banks.

\section{Conclusion}

The rate of discarding blood products is a quality indicator of functioning of blood bank. Every institution should have a well functioning Transfusion committee which should ensure meticulous screening of donors prior to blood donation, sensitization of clinicians on rational use of blood products, training of blood bank personnel.Practicing standard transfusion protocols made by proper policy making and its strict implementation will minimize the discard rate of blood and blood products in the blood banks.

\section{What the study adds to the existing knowledge?}

This study analyzed the reasons for discarding of blood and blood products in the blood bank and suggestedstrategies to minimize the discarding rate to save time, human and financial resources. Every institution should have a transfusion committee with standard transfusion protocols, meticulous screening of donors prior to donation, sensitization of clinicians on rational use of blood products and training of blood bank personnel to minimize the discard rate.

\section{Author's contribution}

Dr. Vimal Mourouguessine contributed to the concept and design of the study, interpreted the data and prepared the manuscript.
Rakesh Balla collected the data. Dr. Nisshanthi Anandabaskar organized the data and prepared the manuscript.

\section{Reference}

1. Pitocco C, Sexton TR. Alleviating blood shortages in a resource-constrained environment. Transfusion. 2005; 45(7)1118-26 doi: 10.1111/j.1537-2995. 2005.00176.x [Crossref][PubMed][Google Scholar]

2. Chavan SK. Determination of rate and analysis of reasons for discarding blood and blood components in a blood bank of tertiary care hospital- a retrospective study. Int J Res Med Sci. 2017;5(3)1111-1115. doi: 10.18203/2320-6012. ijrms20170671 [Crossref][PubMed][Google Scholar]

3. Kanani AN, Vachhani JH, Dholakiya SK, Upadhyay $\mathrm{SB}$. Analysis on discard of blood and its products with suggested possible strategies to reduce its occurrence in a blood bank of tertiary care hospital in Western India. Global J Transfus Med. 2017;2(2)130. doi: 10.4103/ GJTM. GJTM_34_17 [Crossref][PubMed][Google Scholar]

4. Kora SA, Kulkarni K. An analysis of donor blood wastage in a blood bank in an analysis of donor rural Karnataka. J Clin Diagn Res. 2011;5(7)1393-6. [Crossref][PubMed][Google Scholar]

5. Kumar A, Sharma S, Ingole N, Gangane N. Analysis of reasons for discarding blood and blood components in a blood bank of tertiary care hospital in central India- A prospective study. Int J Med Public Health. 2014;4(1)72-4. doi: 10.4103/22308598.127161 [Crossref][PubMed][Google Scholar]

6. Morish M, Ayob Y, Naim N, Salman H, Muhamad NA, Yusoff NM. Quality indicators for discarding blood in the National Blood Center, Kuala Lumpur. Asian J Transfus Sci. 2012;6(1)19-23. doi: 10.4103/0973-6247.95045 [Crossref][PubMed] [Google Scholar]

7. Patil P, Bhake A, Hiwale K. Analysis of discard of whole blood and its components with suggested possible strategies to reduce it. Int J Res Med Sci. 2016;4(2)477. doi: 10.18203/2320-6012. ijrms20160299 [Crossref][PubMed][Google Scholar]

8. Suresh B, Babu KS, Arun R, Chandramouli P, Jothibai DS. Reasons for discarding whole blood and its components in a tertiary care teaching hospital blood bank in South India. J Clin Sci Res. 2015;4(3)213. doi: 10.15380/2277-5706. JCSR.14.052 [Crossref][PubMed][Google Scholar] 
9. Thakare MM, Dixit JV, Goel NK. Reasons for discarding blood from blood bank of government medical college, Aurangabad. Asian J Transfus Sci. 2011; 5(1)59-60. doi: 10.4103/0973-6247.76009 [Crossref][PubMed][Google Scholar]

10. Kaur $P$, Kaur $R$, Masih $V$, Jindal $A$. Incidence and Causes of Wastage of Blood \& Blood Components in a Blood Bank of Tertiary Care Hospital- A Retrospective Study. IOSR-JDMS. 2016;15(9)108110. doi: 10.9790/0853-150904108110 [Crossref] [PubMed][Google Scholar]

11. World Health Organization WHO. Quality systems for blood safety: Introductory module guidelines and principles for safe blood transfusion practice. Geneva. 2002;65-75. [Crossref][ PubMed] [Google Scholar]
12. Guidelines for the blood transfusion services in the United Kingdom 7th ed, London- The Stationery Office. 2005;p-18-77. [Crossref][PubMed][Google Scholar]

13. Vimal M, Sowmya S. Transfusion Transmissible Diseases - Is There a Decreasing Trend in Recent Years?. Nat J Lab Med. 2017;6(1)07-11. doi: $10.7860 /$ NJLM/2017/23339:2190 [Crossref] [PubMed][Google Scholar]

14. Smita M, Binay B, Gopal K, Debasish M, Rashmita P, Pankaj P. Discard of blood and blood components with study of causes - A good manufacture practice. WJPMR. 2017;3(2)172-175. [Crossref][PubMed][Google Scholar] 